Das Schubert-Lied und seine Interpreten 
Sabine Näher

\section{Das Schubert-Lied und seine Interpreten}

Verlag J. B. Metzler

Stuttgart - Weimar 
Die Deutsche Bibliothek - CIP-Einheitsaufnahme

Näher, Sabine:

Das Schubert-Lied und seine Interpreten /

Sabine Näher. - Stuttgart ; Weimar : Metzler, 1996

ISBN 978-3-476-01329-3

ISBN 978-3-476-01329-3

ISBN 978-3-476-03616-2 (eBook)

DOI 10.1007/978-3-476-03616-2

Dieses Werk einschließlich aller seiner Teile ist urheberrechtlich geschützt. Jede Verwertung außerhalb der engen Grenzen des Urheberrechtsgesetzes ist ohne Zustimmung des Verlages unzulässig und strafbar. Das gilt

insbesondere für Vervielfältigungen, Übersetzungen, Mikroverfilmungen und die Einspeicherung und Verarbeitung in elektronischen Systemen.

(C) 1996 Springer-Verlag GmbH Deutschland

Ursprünglich erschienen bei J. B. Metzlersche Verlagsbuchhandlung und Carl Ernst Poeschel Verlag GmbH in Stuttgart 1996 


\title{
Inhalt
}

\author{
Olaf Bär \\ Eine Seelenwanderung 1
}

Juliane Banse

Schuberts Genie ist eben unfaßbar 13

Barbara Bonney

Das Herz öffnen und die Seele zeigen 21

Christian Elsner

Durch verschiedene Gefühlswelten wandern 31

Brigitte Fassbaender

Menschlich und wahrhaftig interpretieren 41

Dietrich Fischer-Dieskau

Ein Dichter in Tönen 55

Irwin Gage

Eintauchen in die Welt der Romantik 75

Matthias Görne

Eingriff in die menschliche Seele 87

Thomas Hampson

Die Uhr unserer Lebenszeit für ein Weilchen anhalten

\section{Robert Holl}

Die ideale Verbindung zwischen Musik und Poesie 111

Graham Johnson

Eine Künstlerpersönlichkeit von universellem Rang

Christoph Prégardien

Mit wirklich großer Musik wird man nie fertig 139 


\title{
Hermann Prey
}

Nicht begeistern - sondern bewegen 149

\author{
Thomas Quasthoff \\ Mut zur Emotion 159
}

Anneliese Rothenberger

Schuberts Lieder sind die innigsten 171

Christine Schäfer

Schubert zu singen macht einfach glücklich 177

Andreas Schmidt

Anwalt der unbekannten Lieder

bekannter Komponisten 185

Peter Schreier

Die glückliche Verbindung von Kunst und Einfachheit 197

Mitsuko Shirai/Hartmut Höll

Konsequent und kompromißlos 209

Biographischer Anhang 223

Nachbemerkung 235

Bildquellen 237 


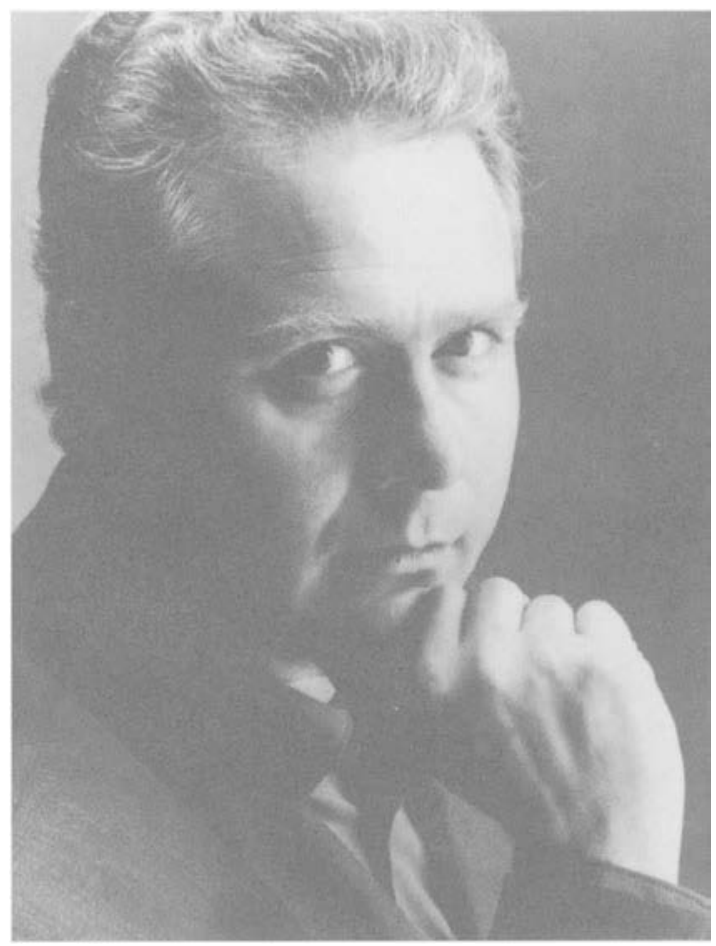

